\title{
Jan Steen's ground layers analysed with Principal Component Analysis
}

\author{
Marya Albrecht ${ }^{* *} \mathbb{D}$, Onno de Noord ${ }^{1,2}$, Sabrina Meloni ${ }^{1 *}$, Annelies van Loon ${ }^{1,3}$ and Ralph Haswell ${ }^{4}$
}

\begin{abstract}
In-depth technical and art historical research into Jan Steen's (ca. 1626-1679) oeuvre has been a focus at the Mauritshuis since 2012, as part of the Partners in Science collaboration with Shell. The aim of this project is to shed light on the chronology of Steen's oeuvre based on the materials he used, since only $10 \%$ of his circa 450 works are dated. Steen worked in different cities within the Netherlands (Haarlem, The Hague, Delft, Leiden and Warmond), each with a distinct artistic community. So far 39 paintings from the Mauritshuis and many other collections in and outside the Netherlands have been analysed. This paper focuses on the ground layers in Steen's paintings. Cross sections were taken of each painting and analysed using SEM-EDX. Principal Component Analysis (PCA) on the resulting dataset was used to find correlations between variables and clustering of samples. Special versions of PCA were explored to analyse pigment identifications and to allow data fusion of this binary data with the quantitative elemental analyses, which is not trivial with normal PCA. The statistical analyses allowed us to group paintings linking them to the different cities where Steen worked and to see outliers in terms of the ground layer composition. Interestingly, the present survey also revealed that apart from commercially prepared grounds, Steen also used grounds prepared in his own studio.
\end{abstract}

Keywords: Jan Steen, Painting technique, Ground layers, Materials analysis, Principal Component Analysis, SEM-EDX, Binary data, Data fusion

\section{Introduction}

Jan Steen (ca. 1626-1679) was a prolific artist from the Dutch Golden Age. He worked from around 1648 to his death in 1679. His oeuvre is large and consists of around 450 paintings, of which the larger part are genre paintings, paintings of everyday life. Steen is particularly known for his humorous depictions of dissolute households, amusements at an inn, quacks and love sick young women. He also painted countless proverbs, as well as interesting history pieces and even a number of highly original portraits. The Mauritshuis has been doing indepth technical and art historical research into Jan Steen's work since 2012, as part of the Partners in Science collaboration with Shell. The aim of this project is to shed light on the chronology of Steen's oeuvre based on the materials he used. The chronology of Steen's oeuvre

\footnotetext{
*Correspondence: m.albrecht@mauritshuis.nl; S.Meloni@mauritshuis.nl ${ }^{1}$ Mauritshuis, Plein 29, 2511 CS The Hague, The Netherlands

Full list of author information is available at the end of the article
}

has been problematic. Since the earliest catalogue of his work, compiled by John Smith in 1838, the number of paintings attributed to him has shifted from 203 to 889 to 376 [1-3]. Presently the oeuvre is estimated to contain around 450 works, of which only 45 are dated by Steen himself. So far, dating Steen's work has been done mostly on stylistic grounds. However, this proves to be difficult with so little dated paintings to compare to undated ones. Furthermore, Steen's painting technique varies from highly refined and detailed to coarse and sketchy. This variation is not only visible in different paintings, but can also be seen within one single painting.

This paper aims to find correlations in the composition of Steen's ground layers throughout his oeuvre. Before a painting on either a wooden or canvas support could be executed a preparatory layer was applied, the ground layer. The function of this layer was to smoothen out irregularities in the support, but also to provide a base for painting with regular absorption. Both colour and texture of the support could be adjusted with the ground layer. 
Materials used for ground layers tend to be cost efficient: typically chalk and earth pigments are used, sometimes coloured with palette scrapings. Commercially-prepared supports seem to have been widely available in the seventeenth century, as references to them in artist's recipes are common. The names of some seventeenth-century primers have survived from contemporary contracts, and inventories of colourmen list pre-primed panels and canvases [4]. A document from the Leiden municipal archives shows that after the frame-maker Leendert van Es passed away, authorization was requested to sell pre-primed canvases and panels. Without someone selling ready-primed supports in Leiden, artists had to go out of their way to obtain them elsewhere [5]. This indicates that painters tended to use local materials, obtained from the colourman or frame-maker in their town. Jan Steen moved often, working in different cities in The Netherlands (Haarlem, The Hague, Delft, Leiden and Warmond), each with distinct artistic communities (see Fig. 1). When buying local artist's supplies every time he moved, his materials might vary in each town he worked in. Were there different types of pre-primed supports available in different cities, distinguishable by the materials that were used? Did Jan Steen buy his supports pre-primed? And if so: did he buy them at a local artist's supplier every time he moved? By investigating the composition of Steen's ground layers in detail we aim to answer these questions.

The availability of painter's materials did not vary greatly per city in seventeenth-century Holland. The range of pigments a painter could use was limited and similar for artists working in, for instance, Delft or Amsterdam. Therefore, it is unlikely that it is possible to distinguish between artistic centers based on the pigments used. To some degree the same applies for the materials used to make ground layers: roughly the same materials are found in all layers analysed in this study. However, by looking in detail at the relative amounts of the elements present in these materials trends can be observed. Also the colour of the ground, or specific pigment combinations or layering can be unique for a certain artist, time period or artistic center [6-8]. Since ground layers are applied quite homogeneously across the surface of a support, samples taken anywhere will most likely be representative of the entire surface. We analysed 39 paintings from the Mauritshuis and many other collections in and outside the Netherlands. Cross sections were taken of each painting and analysed using scanning electron microscopy coupled with energy dispersive X-ray analysis (SEM-EDX). Principal

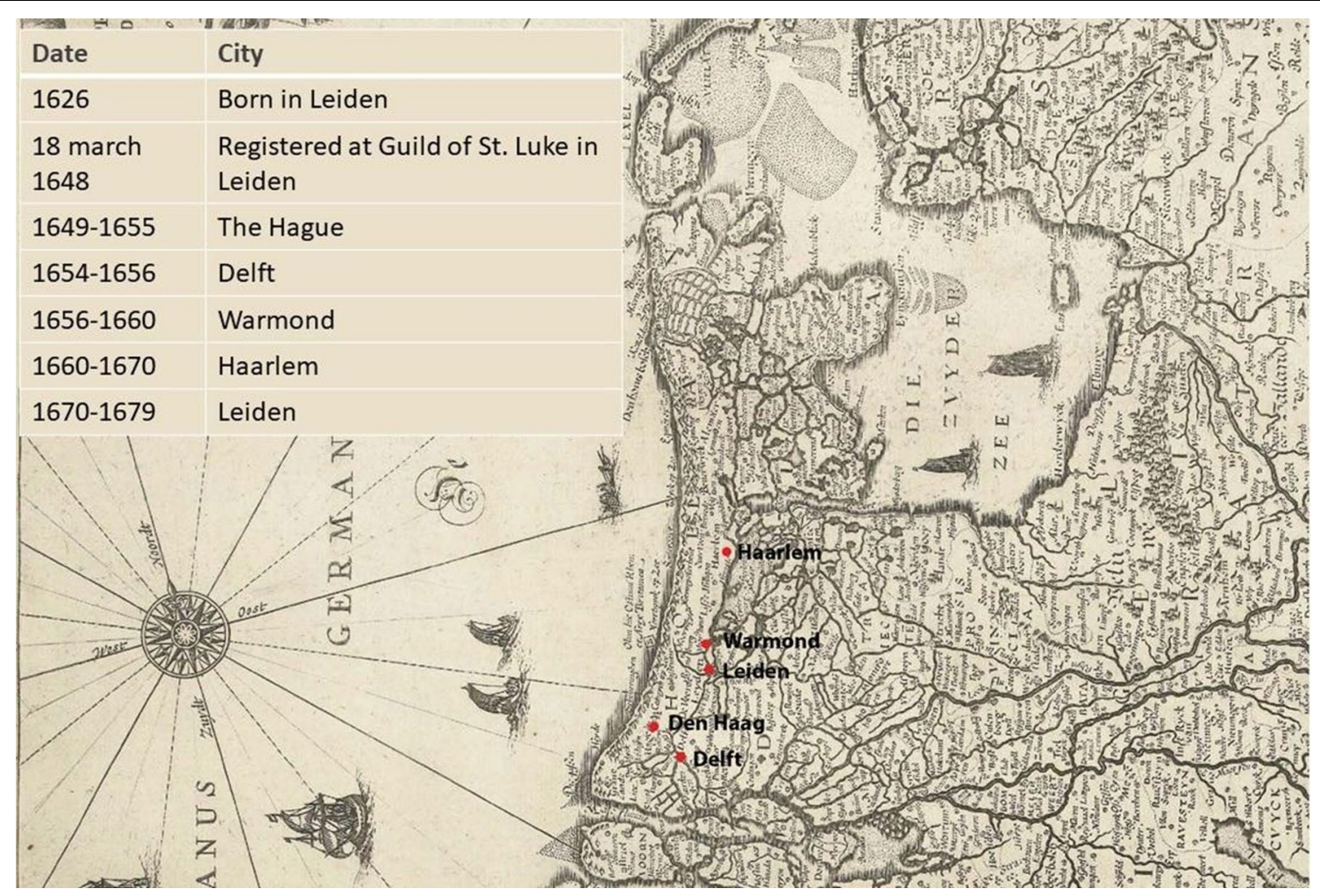

Fig. 1 Contemporaneous map of Holland with cities Steen lived in indicated with red dots 
Component Analysis (PCA) on the resulting dataset was used to find correlations between variables and clustering of samples. Special versions of PCA were explored to analyse pigment identifications and to allow data fusion of this binary data with the quantitative elemental analyses, which is not trivial with normal PCA. The statistical analyses allowed us to group paintings linking them to the different cities where Steen worked and to see outliers in terms of the ground layer composition.

\section{Materials and methods}

\section{Samples, sample preparation and light microscopy}

The starting point for the project was the analysis of the painting technique of the 15 works by Steen in the collection of the Mauritshuis, of which two are signed and dated by the artist. In addition to these initial 15 paintings, samples were taken from 24 , mostly dated, paintings from other collections in and outside The Netherlands to gain more insight into the exact composition of the materials used by Steen (see Table 1 for an overview of all the sampled paintings). This group of 39 sampled paintings spans Steen's entire career, with the earliest painting dating 1646-48 and the latest 1674-78. Approximate dates used in this article are retrieved from the institutions that own the paintings. Both canvases (24) and panels (15) were included. Within this group 17 paintings were dated by the artist himself, serving as a reference for the undated paintings.

Two to nine samples were taken per painting, to be able to determine which layers belong to the ground. All paint samples were embedded in either polyester (Polypol PS230 with M.E.K.-peroxide hardener, Poly-Service Amsterdam, Netherlands) or methacrylate resin (Technovit 2000 LC, Heraeus Kulzer GmbH, Germany) and prepared as cross sections by sanding down the transverse plane. A Leica DM2500 M microscope coupled with a Zeiss Axiocam 512 camera was used to examine the cross sections visually in both normal reflected light (bright and dark field) and ultraviolet light, and photograph them.

\section{SEM-EDX}

After initial investigation with optical microscopy, SEMEDX analysis of the cross sections was done at Shell Technology Centre Amsterdam, using a high-vacuum JEOL 7000F SEM with Noran System Six energy dispersive X-ray system from Thermo Fisher Scientific. The samples were typically examined with an accelerating voltage of $20 \mathrm{kV}$ and a beam current of between 1 and $5.5 \mathrm{nA}$ in backscatter mode. A combination of point and shoot and X-ray elemental mapping was employed. Areas to be measured with point and shoot were carefully selected, making sure to measure an area that was representative of the entire layer. Box-measurements were drawn onto SEM-BSE images manually. To prevent large particles of a single pigment from influencing the results of the measurement, these were avoided or only included in the measurement partially. Several box measurements were done per layer. X-ray elemental mapping was used to provide an overview of the pigments present in each layer.

The composition of the layers was analysed quantitatively using the proza standardless method to determine the relative amounts of the elements found in the various paint layers. Quantification of paint constituents in cross sections using SEM-EDX has been done in previous studies on smalt degradation $[9,10]$ and Vincent van Gogh's ground layers [11]. In these studies the quantitative results were compared to either glass standards or reconstructions with a known composition. Since such standards do not exist for seventeenth-century ground layers, the results in this study can only be deemed semiquantitative and may be prone to systematic errors due to the heterogeneous nature of the samples. However, as the morphology of the various ground layers does not vary greatly between different samples and, as such, the systematic errors will remain constant between samples, comparison of the data is still possible.

For the elemental composition a normalized quantification of 15 selected elements that were detected in the ground layers, namely $\mathrm{Na}, \mathrm{Mg}, \mathrm{Al}, \mathrm{Si}, \mathrm{P}, \mathrm{S}, \mathrm{Cl}, \mathrm{K}, \mathrm{Ca}, \mathrm{Ti}$, $\mathrm{Mn}, \mathrm{Fe}, \mathrm{Co}, \mathrm{Cu}$ and $\mathrm{Pb}$, was done. This was based on the weight percentages of the oxides of the chosen 15 elements. Since multiple measurements were done per layer, per cross section, this resulted in a large dataset. All data was recorded in an Excel-spreadsheet.

\section{Pigment identification}

Pigments were identified based on careful visual examination of the cross sections under normal reflected light and ultraviolet light, looking at the colour, size and shape of the pigment particles, combined with their particle morphology as revealed by the SEM backscattered-electron images and elemental information obtained from SEM-EDX spot measurements on specific particles and elemental mappings of the entire cross-section surface. This resulted in a binary dataset: 27 pigments were listed that were either present in the ground layer or not (see Table 2 for an overview of the pigments found in this study). This data was added to the Excel-spreadsheet.

\section{Principal Component Analysis}

Multivariate analysis of the different datasets was performed using Principal Component Analysis (PCA) [12, 13] in the Matlab 7.13 environment (The MathWorks, 


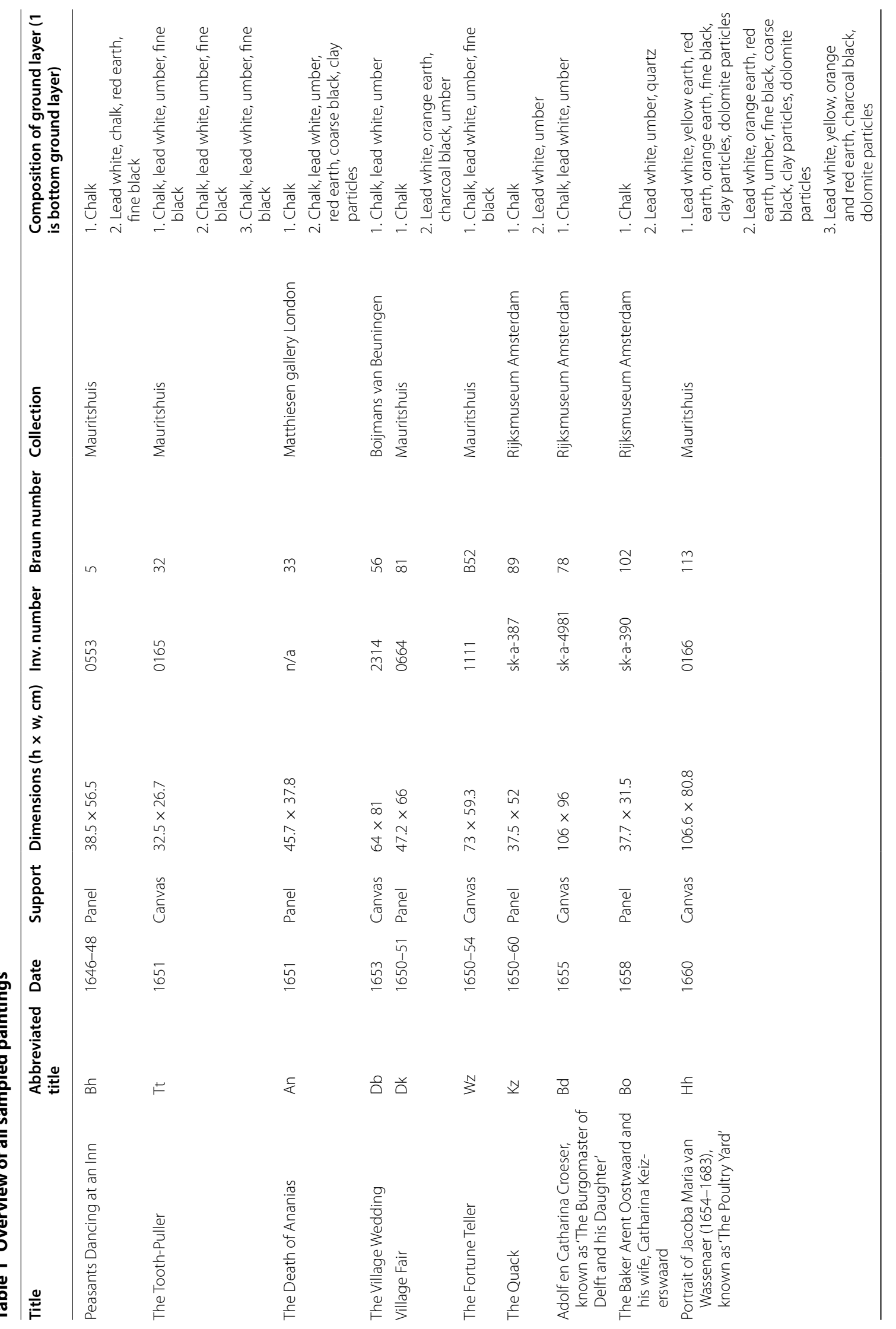




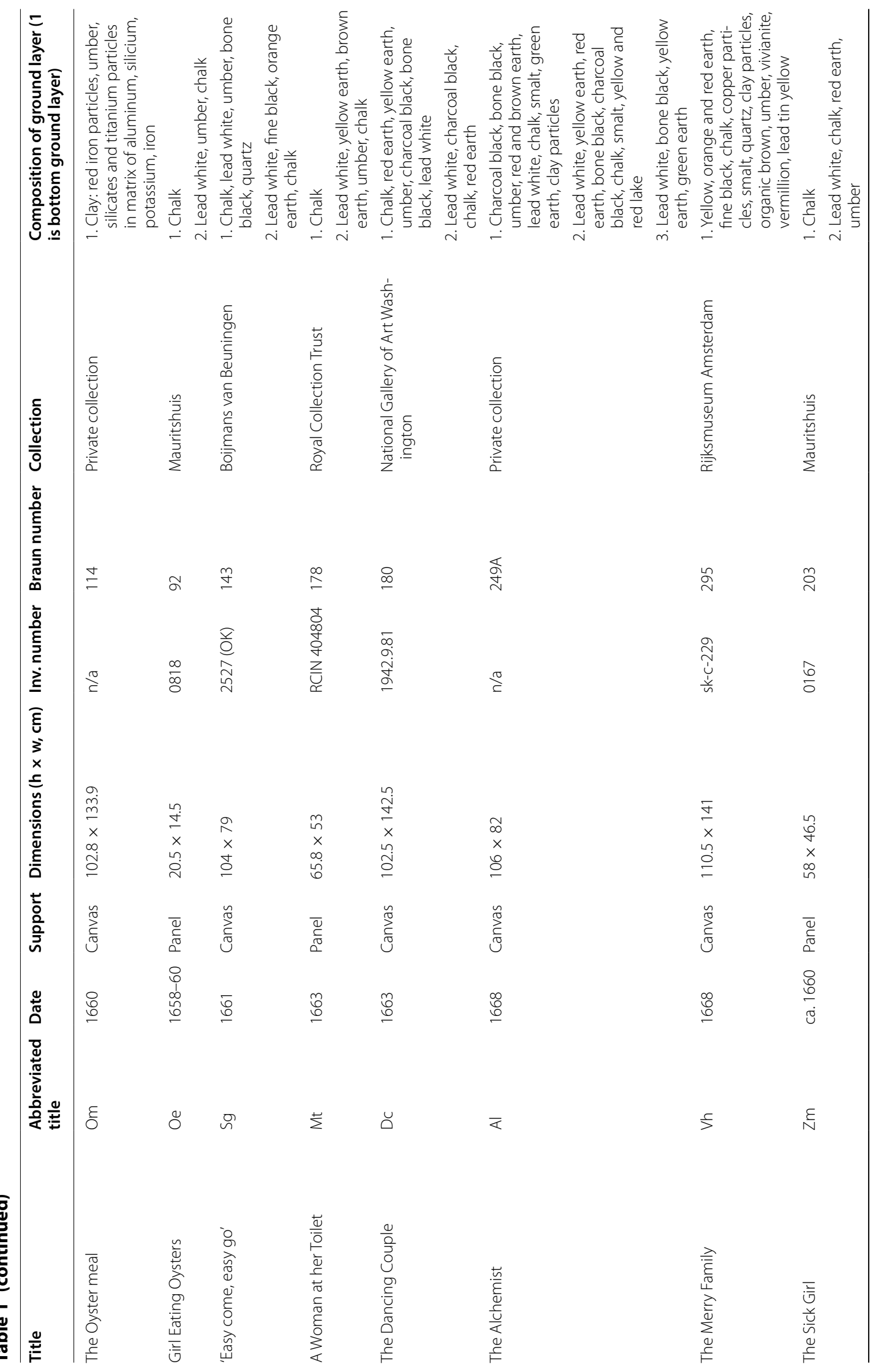




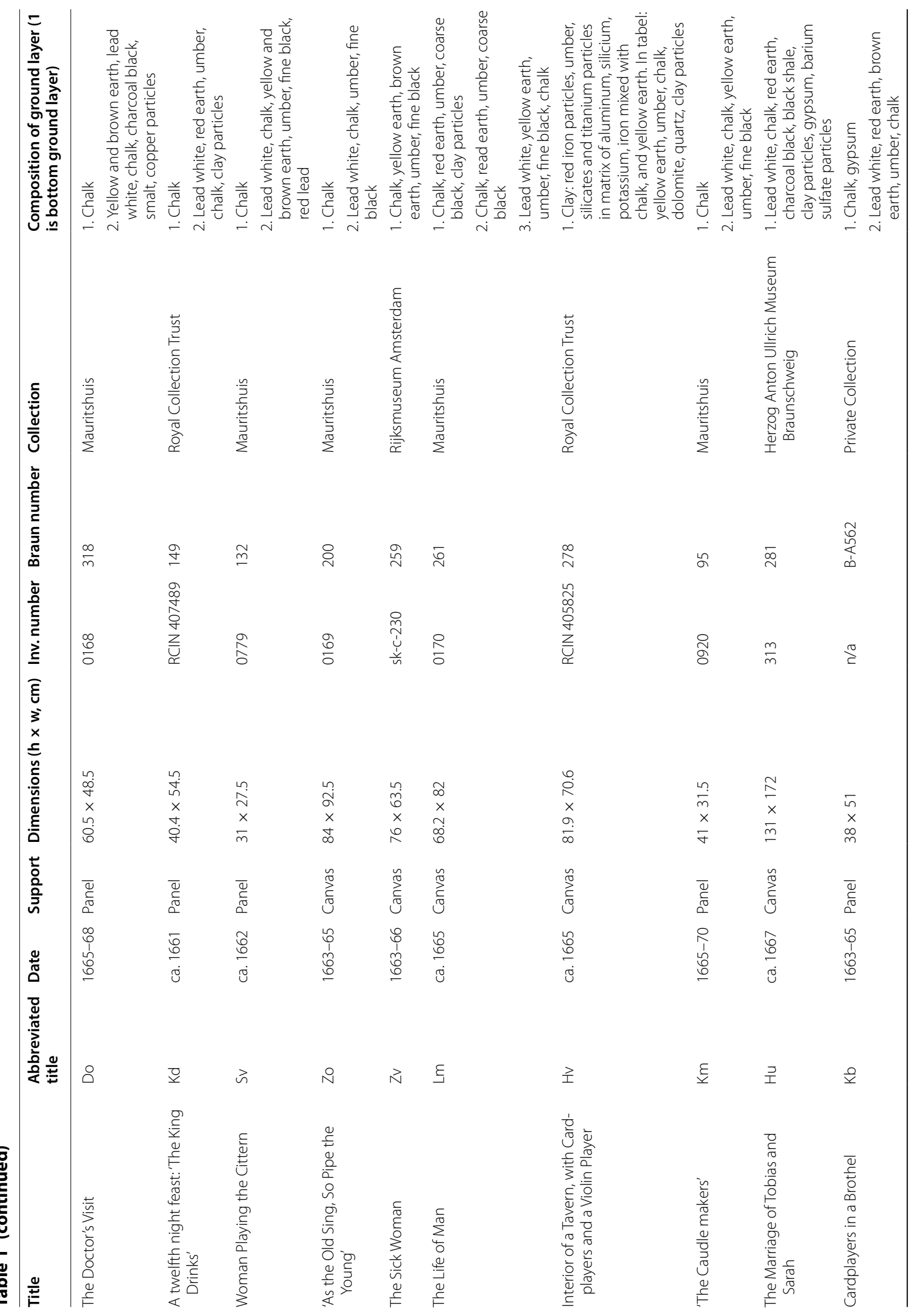


Albrecht et al. Merit Sci <wide> <wide> (2019) 7:53

Page 7 of 17

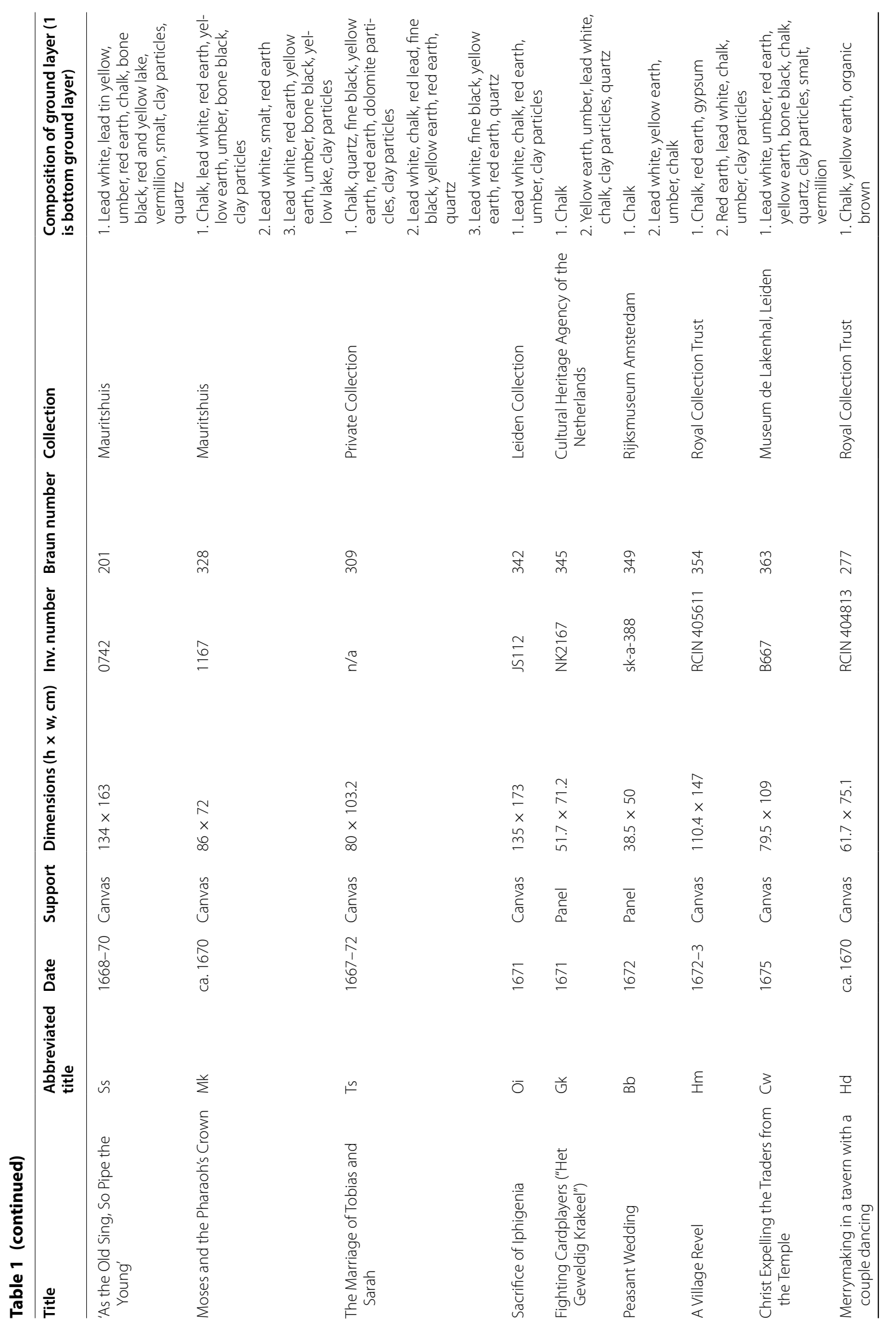




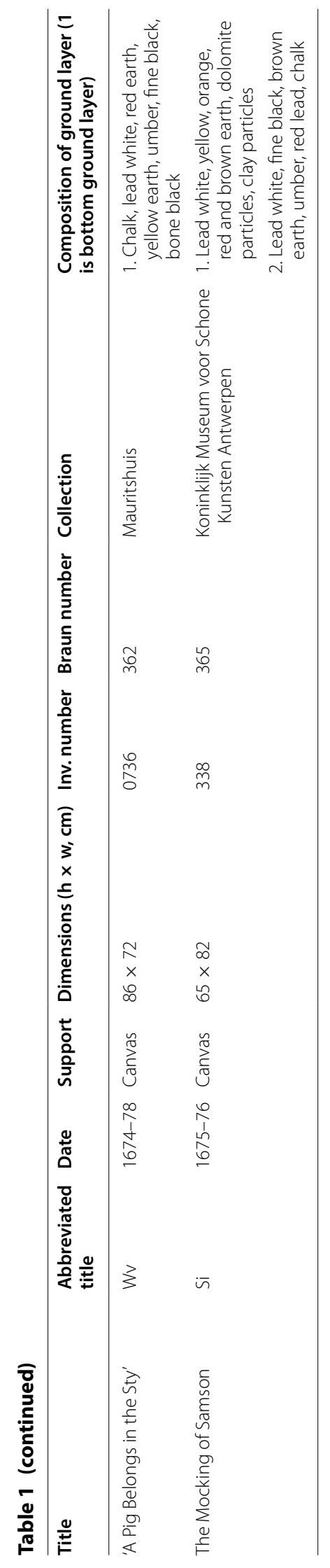


Table 2 Overview of pigments encountered in the ground layers

\begin{tabular}{|c|c|c|}
\hline Pigment & Abbreviation & $\begin{array}{l}\text { Frequency } \\
\text { in ground } \\
\text { layer } 1\end{array}$ \\
\hline Lead white & Iw & 15 \\
\hline Red earth & $\mathrm{ra}$ & 15 \\
\hline Yellow earth & ga & 11 \\
\hline Orange earth & oa & 3 \\
\hline Brown earth & ba & 3 \\
\hline Umber & om & 16 \\
\hline Organic brown & $\mathrm{rb}$ & 2 \\
\hline Fine black & $\mathrm{fz}$ & 7 \\
\hline Coarse black & $g z$ & 1 \\
\hline Charcoal black & hz & 3 \\
\hline Bone black & bz & 7 \\
\hline Chalk & $\mathrm{kr}$ & 35 \\
\hline Dolomite & do & 4 \\
\hline Gypsum & gi & 2 \\
\hline Clay particles & kl & 12 \\
\hline Smalt & sm & 4 \\
\hline Green earth & gr & 1 \\
\hline Lead tin yellow & It & 2 \\
\hline Vermillion & ve & 3 \\
\hline Red lake & $\mathrm{rl}$ & 1 \\
\hline Yellow lake & gl & 1 \\
\hline Quartz & kw & 6 \\
\hline Red lead & $\operatorname{lm}$ & 0 \\
\hline Copper particles & ko & 1 \\
\hline Barium sulfate particles & bs & 1 \\
\hline Vivianite & vi & 1 \\
\hline Black shale & sz & 1 \\
\hline
\end{tabular}

Natick, MA, USA), partly using the PLS Toolbox 7.3.1 (Eigenvector Research, Manson, WA, USA).

The SEM-EDX data was analysed with standard PCA after autoscaling (standardizing) the variables. In first instance PCA was done on the individual sample data for data cleaning purposes. Outliers were detected and corrected or deleted, after which the remaining samples were averaged per painting.

Separate analyses were done per ground layer, all the top ground layers (this can be either the first, the second or the third layer) and all layers together. Special versions of PCA were used to allow the analysis of the binary pigment data and data fusion with the ratio-scaled elemental data.

The pigment data can be seen as categorical and such data can be analysed with non-linear PCA using optimal scaling approaches [14]. Binary data can be considered a special case of categorical data and it has been proven that non-linear PCA using optimal scaling results can be achieved by performing PCA on the standardized binary variables $[15,16]$.

Simultaneous analysis of the quantitative SEM-EDX and the binary pigment data needs a multi-block or data fusion approach that can handle data blocks obtained at different measurement scales. Different strategies are possible to perform such heterofusion [17] and in the present study optimal scaling combined with Consensus PCA (CPCA) was chosen. CPCA is a method to simultaneously analyse several blocks of variables measured on the same objects $[18,19]$. Overall variability among the different blocks can be summarized in consensus directions, which are represented in so-called super scores and super loadings. Block scaling was applied first to give each block the same prior weight.

\section{Results and discussion}

There is a considerable amount of variation in the analysed dataset, both regarding the number of ground layers and their composition. In several paintings, layers were found consisting of only one pigment, while in other paintings 14 pigments were combined to form the ground layer. At most Steen used three ground layers, while there are also instances of using only one ground layer. PCA was used to explore the datasets in a multivariate way.

\section{PCA of elemental and pigment data}

PCA on the quantitative elemental data of the bottom ground layers roughly shows four clusters in the score plot of the first two PCs (see Fig. 2a). This initial clustering separates the canvas paintings from the panel paintings. All 15 panel paintings (cluster 3) contain a bottom ground layer made of chalk, a calcium carbonate, as indicated by the large loading of calcium $(\mathrm{CaO})$ in this direction in the corresponding loading plot (see Fig. 2b). Apart from the panel paintings, three other clusters can be discerned in Fig. 2a: bottom ground layers (cluster 4, contains 4 paintings) consisting mainly of iron-containing earth pigments, as indicated by the loadings of silicon $\left(\mathrm{SiO}_{2}\right)$, aluminium $\left(\mathrm{Al}_{2} \mathrm{O}_{3}\right)$, iron $\left(\mathrm{Fe}_{2} \mathrm{O}_{3}\right)$ and magnesium $(\mathrm{MgO})$; bottom ground layers consisting mainly of lead white, a basic lead carbonate (cluster 1, with 6 paintings), as indicated by the large loading of lead $(\mathrm{PbO})$ in this direction; and bottom ground layers consisting of a mix of lead white and chalk (cluster 2 with 8 paintings).

The binary pigment data was analysed with nonlinear PCA using optimal scaling. Since the input data consists of zeroes and ones, objects (paintings) and variables (pigments) may coincide in score and loading plots. Indeed, all paintings on panel with only chalk in the bottom ground layer coincide in Fig. 3a (indicated by the arrow). The first dimensions are dominated by the number of 

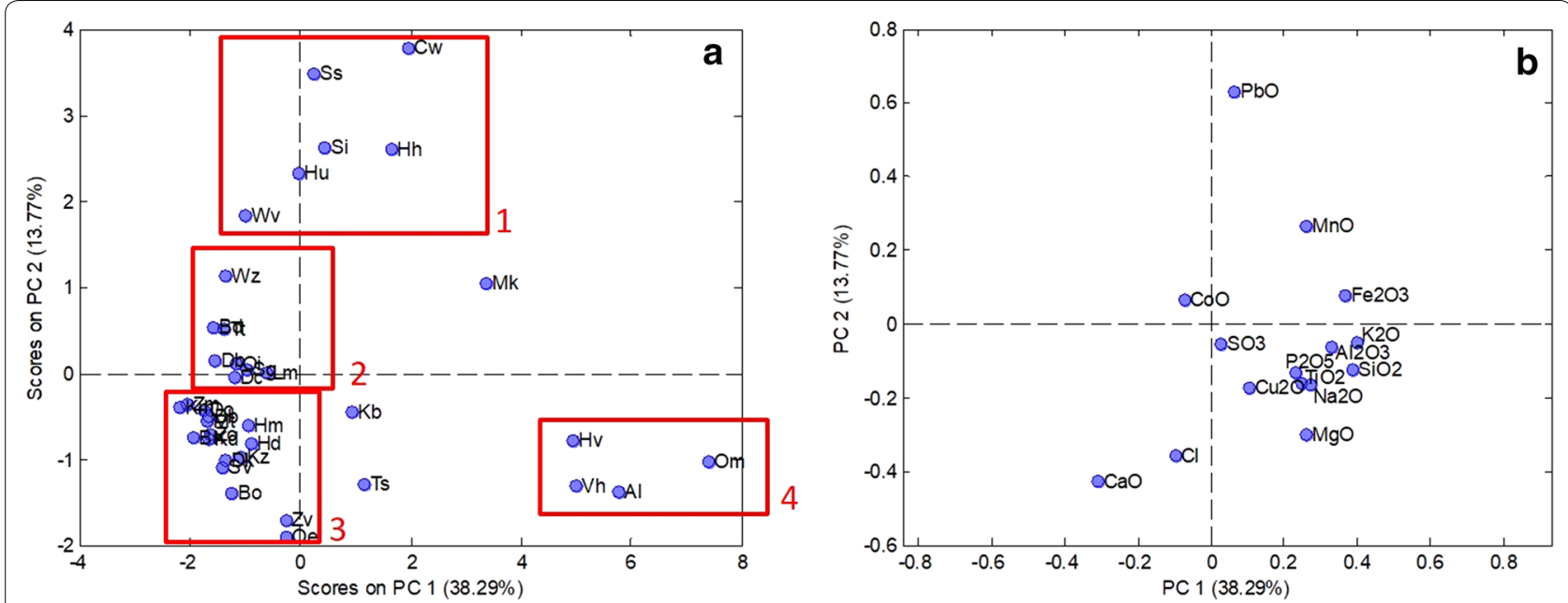

Fig. 2 PCA scores (a) and corresponding loadings (b) for the quantitative elemental data on the first ground layers with clusters indicated. In the score plot (a) the paintings are presented by their abbreviated titles (see Table 1). In the loading plot (b) the elements are presented as their oxides
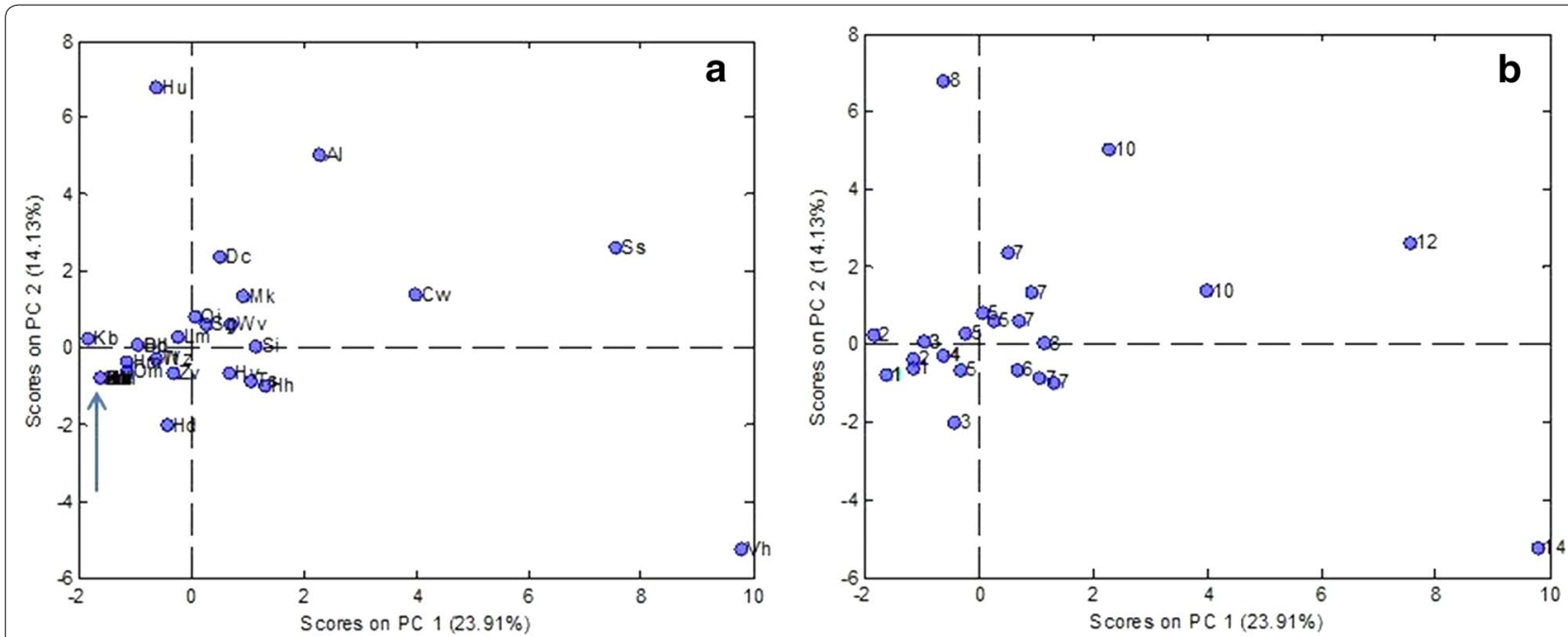

Fig. 3 PCA on pigment data; a labels= paintings, $\mathbf{b}$ labels = number of pigments identified in bottom ground layer

pigments present in the bottom ground layer, as shown in Fig. 3b. Since the presence of a pigment provides neither information on its (relative) amount, nor on its chemical composition, only limited information can be obtained for dating purposes. This also explains why the matrices with pigment and elemental data are only weakly correlated. For the first ground layer this correlation was found to be 0.43 using Indahl's "similarity of matrices index" [20]. Nevertheless, the two data blocks can be fused after optimal scaling followed by block scaling and analysed by means of Consensus PCA. The multi-block data analysis results are illustrated in Fig. 4, where three paintings immediately pop up as exceptional in the PC3/
PC4 score plot (see Fig. 4a). The Merry Family (Vh) is an outlier on $\mathrm{PC} 3$, because it has by far the highest concentration of copper $\left(\mathrm{Cu}_{2} \mathrm{O}\right)$ in the elemental dataset, and it is the only one with vivianite (vi), an iron phosphate, and copper-containing particles (ko) in the pigment dataset (see Fig. 4b). The Alchemist (Al) is an outlier on PC4 due to its highest concentration of phosphorus $\left(\mathrm{P}_{2} \mathrm{O}_{5}\right)$, caused by the ample use of bone black, mainly composed of calcium phosphate and carbon, in this layer. The presence of green earth (ga), a complex silicate of $\mathrm{Fe}, \mathrm{Mg}, \mathrm{Al}$ and $\mathrm{K}$ (mainly minerals as celadonite and glauconite) is distinct as well, causing the high concentration of magnesium $(\mathrm{MgO})$ and adding to the distinctiveness of this 

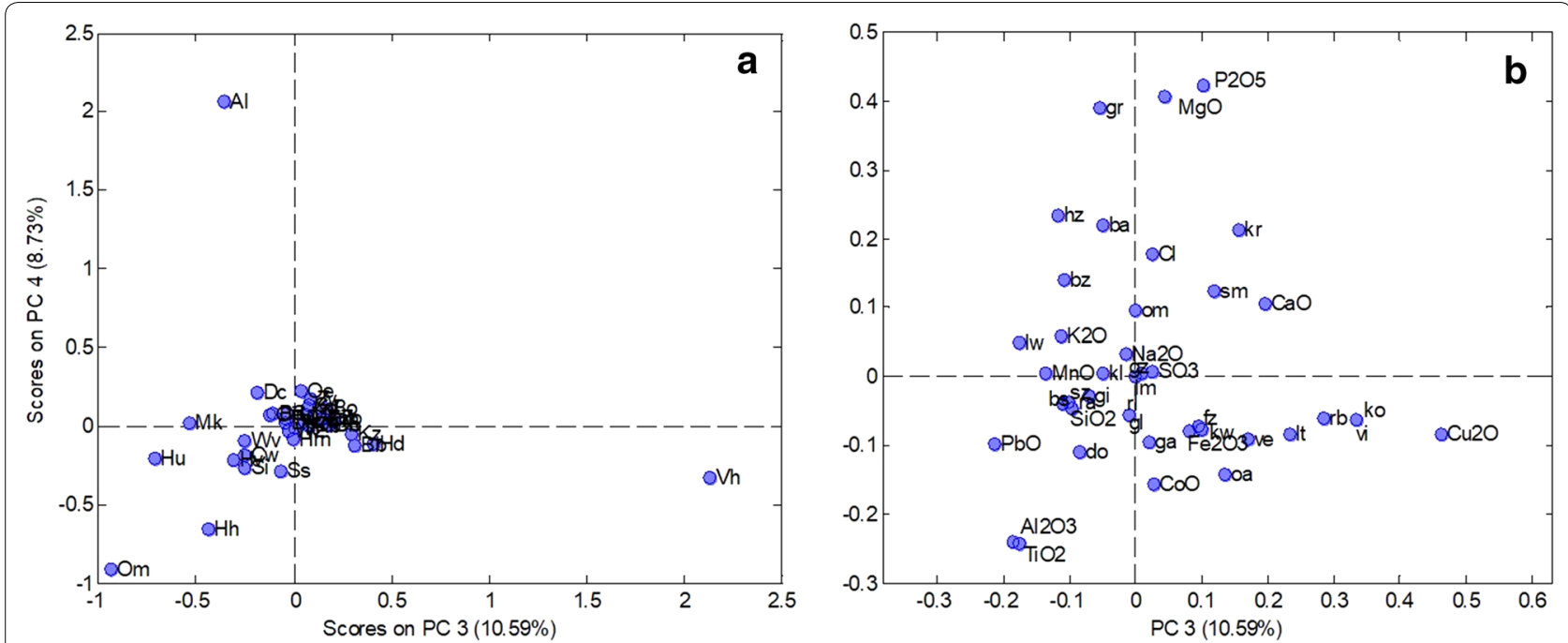

Fig. 4 Multi-block PCA on elemental and pigment data of bottom ground layer. Scores (a) and loadings (b) on PC3 and PC4

layer. The Oyster Meal (Om) is an extreme data point in the lower left corner of the score plot due to its highest concentration of aluminium $\left(\mathrm{Al}_{2} \mathrm{O}_{3}\right)$ and titanium $\left(\mathrm{TiO}_{2}\right)$, caused by the iron-containing earth pigments that make up this layer.

\section{Panels}

All paintings on panel contain two ground layers, of which the bottom layer consists of only chalk with the exception of Cardplayers in a Brothel (ca. 1663-65). In this painting the bottom ground layer contains some gypsum as well. In the PCA score plot this painting $(\mathrm{Kb})$ is placed outside of the cluster of panel paintings, showing the abilities of this method to find outliers (see Fig. 2a).
The second ground layers on panels do show variation. They are all light-coloured, varying in tone from cream to light yellow to light grey. PCA of the second ground layers of all paintings was done to further analyse the similarities between panel paintings.

A large cluster can be seen in the score plot for the second ground layer (see Fig. 5a). This group of panel paintings contains a second ground layer based on lead white, mixed with red and yellow earth, umber and chalk. The composition of this layer is indicated by the loadings of calcium $(\mathrm{CaO})$ and lead $(\mathrm{PbO})$ on either side of the cluster in the corresponding loading plot (Fig. 5b). The clustering of these paintings can be seen in the first, second, third and fourth dimension,
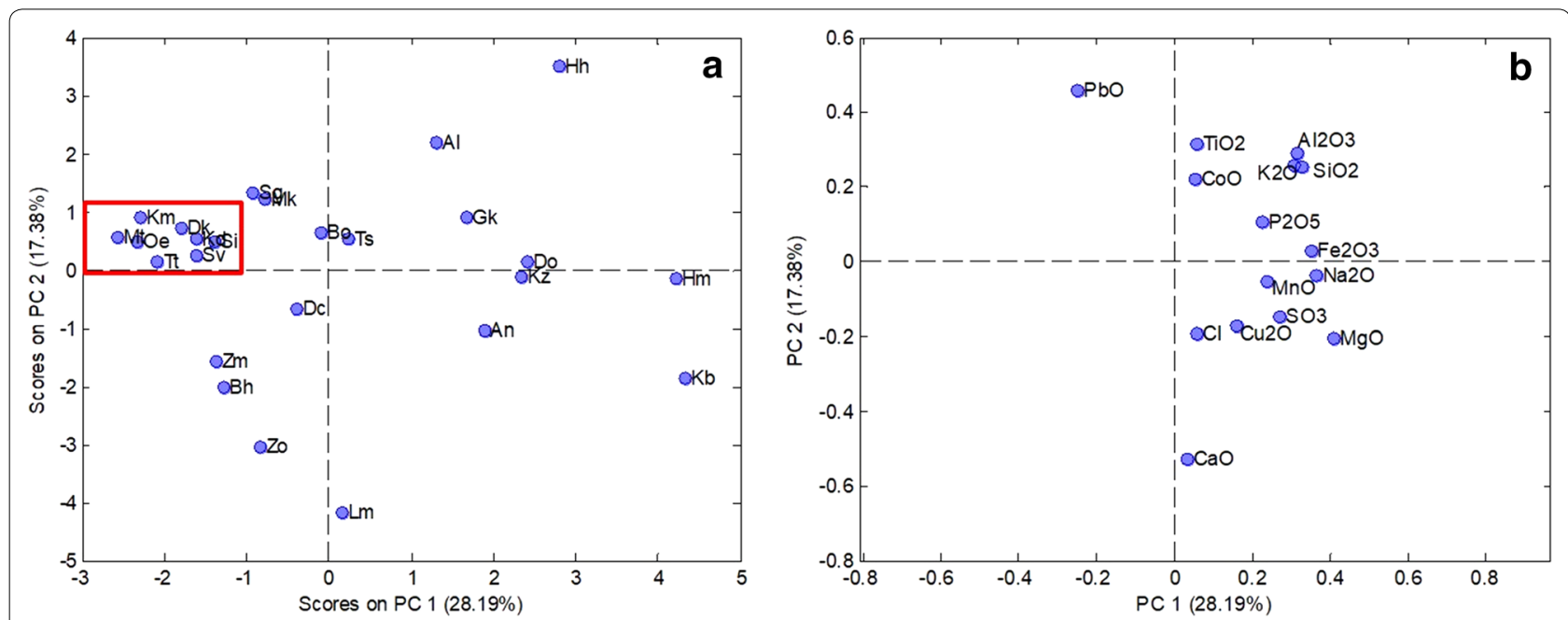

Fig. 5 PCA scores (a) and loadings (b) for the elemental data on the second ground layers, with cluster of panel paintings marked in red 
meaning there's little variance between the paintings. Only one painting dated by Steen himself (A Lady at her Toilet, Mt) falls in this cluster, dated in 1663 when Steen was working in Haarlem. A Twelfth Night Feast (Kd, ca. 1661), Lady Playing the Cittern (Sv, ca. 1662) and The Caudle Makers (Km, ca. 1665-70) are all dated in the Haarlem period and seem to fit in well with this clustering. On Lady Playing the Cittern, the second ground layer has a slightly different composition, it also contains red lead. With the elemental analysis done with SEM no distinction is made between the types of lead compound present and therefore this does not show up as an outlier in PCA. It's worth noting that these panel paintings are all painted on standard-sized panels (see Table 1). It seems likely that standardsized panels were sold to artists ready to go, with both ground layers already applied to them.

Two other paintings dated earlier are clustered with this group of Haarlem paintings based on the composition of their second ground layers. Girl Eating Oysters (Oe) is dated slightly earlier, around 1658-1660. Could it be that this painting needs to be dated later and it was painted in Haarlem?

Village Fair (Dk), dating 1650-1651 also falls in the cluster of panel paintings from Haarlem on PC1-4. However, this painting is probably not painted in Haarlem since it has an underdrawing which is closely related to Steen's teacher in Den Haag, Jan van Goyen, and has all the characteristics of a painting from Jan Steen's early career. Indeed, on PC5 (which explains $8.9 \%$ of the variation in the data) it is not in the cluster.

Apart from this large cluster, no further trends can be observed in Steen's ground use for panel paintings. Several other paintings are clustered together or overlap in the score plot in the first two dimensions, but are placed far apart in dimensions 3-6. This is the case for The Quack (Kz) and Doctor's Visit (Db), and Dancing Peasants at an Inn (Bh) and The Sick Girl (Zm). Perhaps a separate PCA of the data from the 15 panel paintings could reveal more similarities between the second ground layers found on Steen's panels, although the precision of the data limits the usefulness of the results for small datasets.

\section{Canvas}

The Hague, Delft (1649-1656)

All the analysed canvas paintings made in The Hague and Delft show a similar composition of the ground layers. The ground layers on these paintings are light in colour and consist mainly of chalk, lead white with some umber and/or fine carbon black mixed in. Three of the four analysed paintings from this period contain only one ground layer. The fourth painting, The Tooth-Puller (Tt) from the Mauritshuis, is dated 1651 by the artist and contains three ground layers (see Fig. 6). Remarkably, these three ground layers all contain the same pigments, just mixed in different quantities. From X-radiographs it has become clear that the canvas for this painting was cut out of a larger part of ready-primed canvas: cusping, the wavy
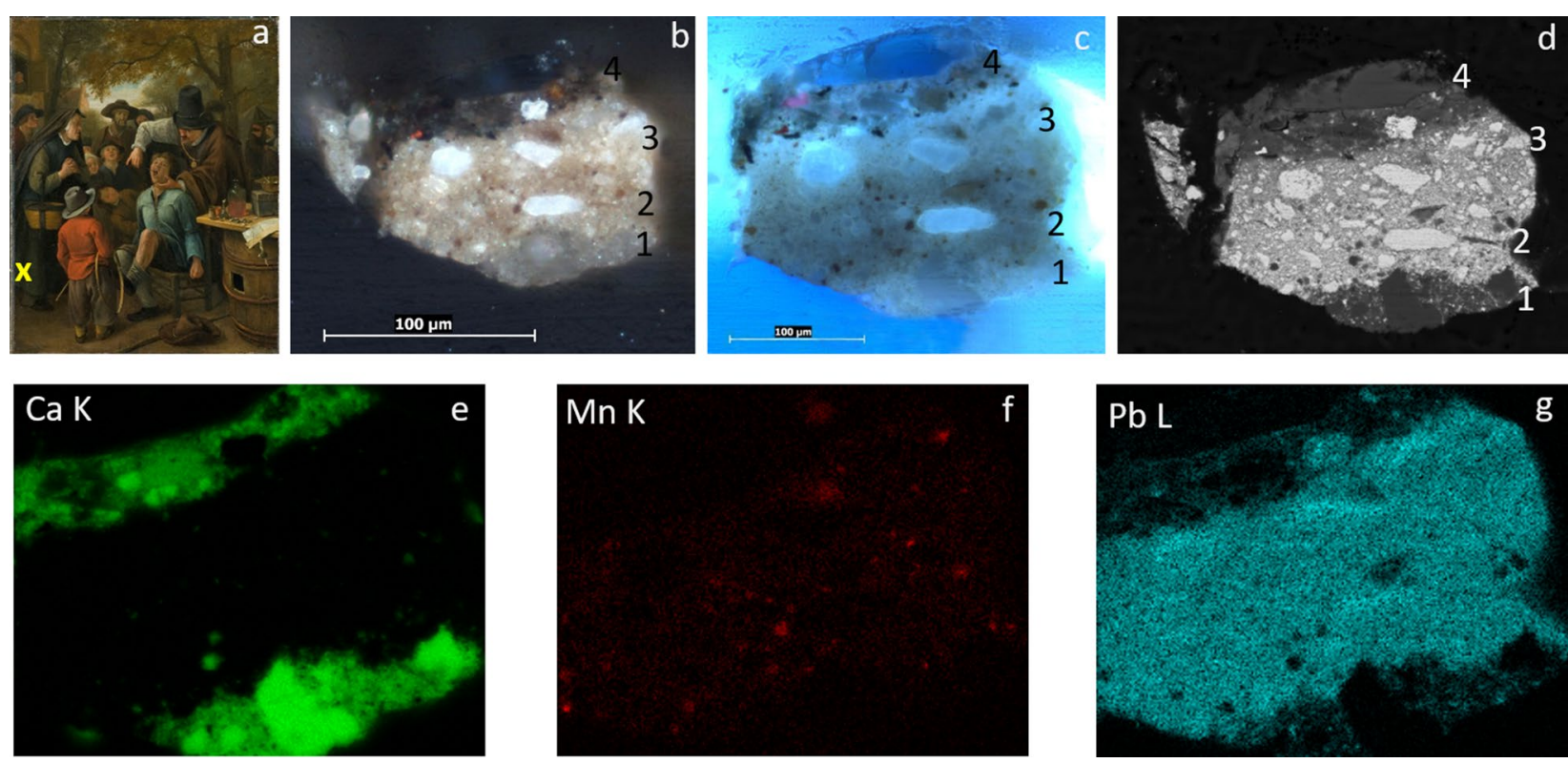

Fig. 6 a The Tooth-Puller, 1651, oil on canvas, overview with cross section location marked with yellow $x$. b Cross section shown in bright field, layers 1-3 are the ground layers. $\mathbf{c}$ Cross section shown in UV. $\mathbf{d}$ Backscatter electron image at $\times 500$ magnification. $\mathbf{e}-\mathbf{g}$ Elemental mappings of different elements, indicating the presence of chalk, lead white and umber 
deformations of the weave that occur along the edges of a canvas when it is first stretched onto a strainer, can only be seen on one side of the canvas and it does not correspond to the format of the painting. It's unclear whether Steen did this more often, so far, no other examples have been found. This ground layer seems typical for Den Haag and Delft. Similar light ground layers, mixtures of lead white and chalk tinted with umber, have been found in paintings by other Delft artists like Vermeer and Pieter de Hooch [21, 22].

\section{Warmond (1656-1660), Leiden (1670-79)}

From Steen's brief period in Warmond, a village close to Leiden, only one canvas painting was analysed. This is Portrait of Jacoba Maria van Wassenaer (also known as 'The Poultry Yard', Hh). The canvas contains three ground layers, consisting mainly of lead white tinted with yellow and red earth pigments. X-radiographs show that the canvas was individually primed, since cusping was seen on all four sides of the painting. Several other paintings on canvas from Leiden, where Steen returned in 1670 and lived until his death in 1679, have been analysed. Some of these paintings are clustered with 'The Poultry Yard' based on the composition of the bottom ground layer. In Christ Expelling the Traders from the Temple $(\mathrm{Cw})$, dated by Steen in 1675, one ground layer is present consisting mainly of lead white tinted with umber, earth pigments and bone black. Both The Mocking of Samson (Si) and 'A Pig Belongs in the Sty' (Wv) contain a comparable lightcoloured ground layer, made predominantly of lead white tinted with some iron-containing earth pigments, umber and bone black. It seems this type of ground was common for Steen in Leiden. In the score plots for PCA on the bottom ground layers these paintings are placed close together, in the first 4 dimensions.

The Mocking of Samson is not lined in later conservation treatments, so the support provides detailed information on its preparation. The canvas is still stretched on its original strainer. The tacking margins are completely intact and show remnants of thread from when the canvas was laced into a larger strainer during painting. On the top and bottom of the canvas the selvedge was present. This all shows that this canvas was individually prepared. The composition of the ground layer, however, closely resembles other paintings from Leiden. This could indicate that the canvas was prepared individually, but not at the artist's studio and was probably commercially available.

The large canvas painting A Village Revel $(\mathrm{Hm})$ contains two ground layers, of which the bottom one consists of chalk and some red earth. The second, top ground layer is dark red in colour and contains predominantly red earth. The dark red ground layer plays a role in the composition, shimmering through thin paint layers in several areas. In other paintings with a medium or darkcoloured ground layer Steen obscured the darker ground by covering it with one or two more ground layers, for instance in Life of Man (c. 1665), where a light gray layer containing lead white, yellow earth, umber, fine black and chalk has been applied over the red ground. In The Alchemist (1668), a dark gray bottom ground layer was covered with lighter ground layers before painting. The composition of the second ground layer in A Village Revel with predominantly red earth seems to correspond with layers used more frequently in Haarlem, even though this painting is dated by Steen himself in 1673, his late period in Leiden. However, to have this darker red ground as a second/top ground layer, where it also plays a role in the composition, is exceptional in Steen's oeuvre.

\section{Haarlem (1660-1670)}

Steen's Haarlem period was the most productive period in his career. In this study 18 paintings from Haarlem were analysed. In Haarlem Steen started using strongly coloured ground layers. A cluster of four paintings containing such a ground can be seen when analyzing the bottom ground layers with PCA (see cluster 4, Fig. 2a). This cluster contains The Alchemist (Al), Interior of a Tavern with Card Players and a Violin Player (Hv), The Oyster Meal (Om) and The Merry Family (Vh). In three of these four paintings just one ground layer is used, consisting of mainly earth pigments and with a red colour. The Oyster Meal is dated 1660 by the artist, the year Steen moved from Warmond to Haarlem. The similarities in colour and composition of the ground layer with other Haarlem paintings suggest that this painting was made after the artist moved. The Merry Family is dated 1668 by Steen himself (see Fig. 7), making a date around 1668 likely for Interior of a Tavern with Card Players and a Violin Player as well.

The Alchemist, another painting dated by Steen in 1668, is clustered with the aforementioned paintings as well. The bottom ground layer has a similar elemental composition, but is very dark gray in colour. On top of this dark gray layer, two more layers were added, one being a warm beige colour and the top layer being lighter and cool gray. Apart from its unusual colour (this is the only dark gray ground layer encountered in this project), the bottom layer also contains some atypical pigments for ground layers, such as smalt and green earth. The same goes for the ground layer of The Merry Family, which contains smalt, vivianite, vermillion and lead-tin yellow next to earth pigments and chalk. Most likely both these layers were applied in the studio, using palette scrapings mixed with earths and chalk. 


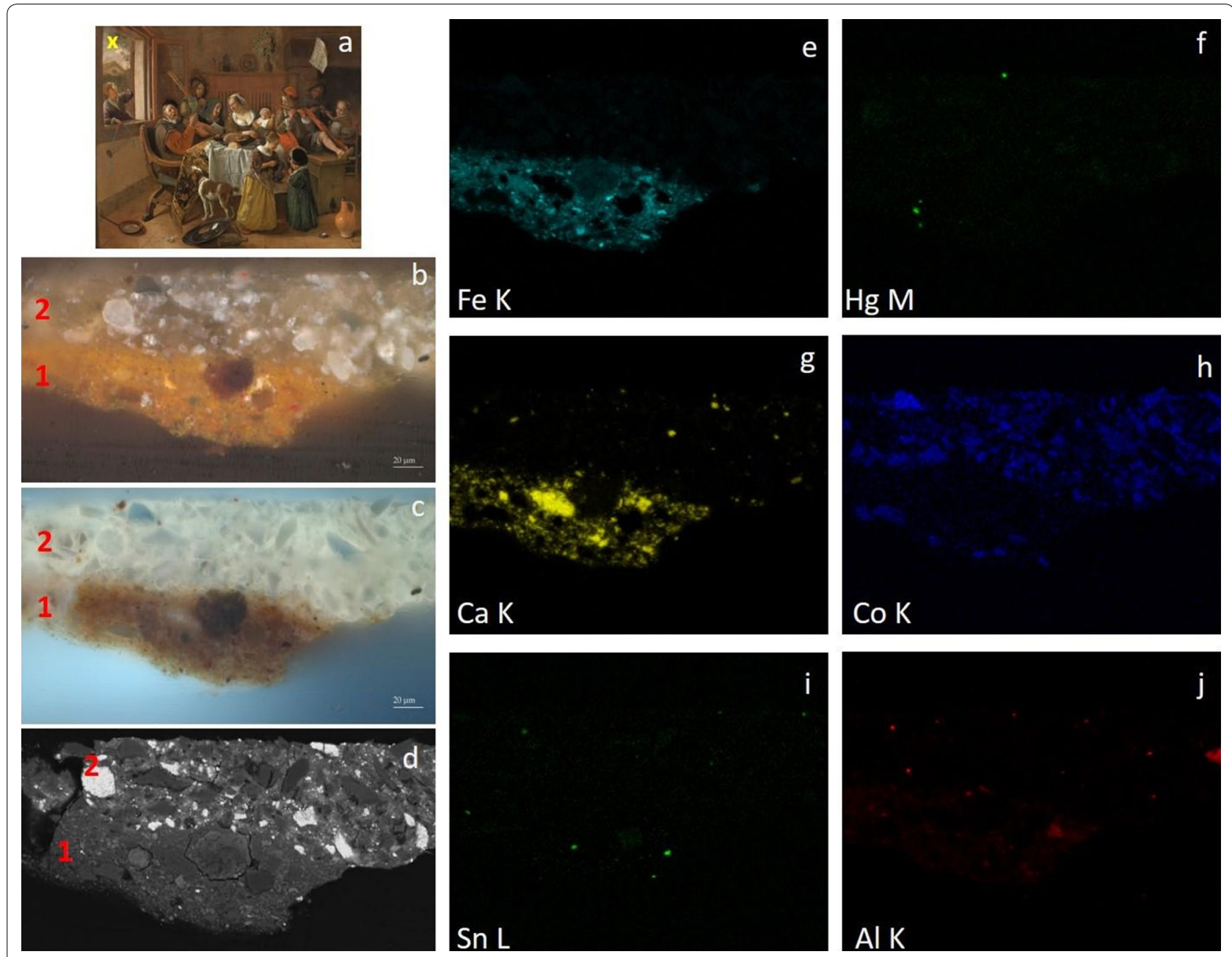

Fig. 7 a The Merry Family, 1668, oil on canvas. Overview image with cross section location marked with yellow X. b Cross section shown in bright field, layer 1 is the ground layer. c Cross section shown in UV. $\mathbf{d}$ Backscatter electron image at $\times 500$ magnification. $\mathbf{e}-\mathbf{j}$ Elemental mappings of different elements, indicating the presence of earth pigments, lead tin yellow, vermillion and smalt

Since the same colour can be achieved by mixing different pigments in different ratios, not all coloured grounds are clustered using PCA. The Life of Man (Lm), a painting on canvas dating around 1665, contains a bright red bottom ground layer. However, since this layer contains more chalk than the other red grounds it is not clustered together. The same goes for The Marriage of Tobias and Sara (ca. 1667-68, Hu), from the collection of the Herzog Anton Ulrich Museum in Braunschweig. Here the red ground layer is a mixture of lead white, coloured with red earth, charcoal black and black shale (a type of black earth pigment consisting mainly of aluminum and silicon). Because of the higher quantity of lead present in this layer the painting is placed in cluster 1 instead of cluster 4 with the other coloured ground layers. Even though the paintings are not clustered together based on their elemental composition, dating them in Haarlem seems highly likely because of the red colour of the ground layer.

The cluster of paintings containing a bottom ground layer with only chalk also contains four paintings on canvas, besides the panel paintings: 'As the Old Sing, So Pipe the Young' (Zo), Merry-making in a Tavern with a Couple Dancing (Hd), The Village Revel (Mh) and The Sick Woman $(\mathrm{Zv})$ These paintings vary in date, with two paintings dating around 1663-65, one around 1670 and one being dated by Steen himself in 1672. With PCA, Merrymaking in a Tavern with a Couple Dancing (ca. 1670, Hd) and The Sick Woman (ca. 1663-65, Zv) are also clustered in a separate analysis of only the top ground layers. Both these paintings contain only one ground layer, consisting of chalk mixed with some earth pigments. It seems that these paintings are closely related in composition of the ground layer and should therefore be dated closer 
together. Based on the results of other paintings analysed from Steen's Haarlem period it seems more likely that Merry-making in a Tavern with a Couple Dancing should be dated some years earlier and both paintings were made in Haarlem.

\section{Ground layers applied in the studio}

The other 'As the old sing, so pipe the young' (Ss) is a large painting on canvas stylistically dated ca. 1668-70, containing one ground layer made up of many pigments: large and fine lead white, lead tin yellow, umber, red earth, chalk, bone black, red lake, yellow lake, vermillion, smalt, feldspar and quartz (see Fig. 8). The ground has been applied with a palette knife and is irregular in thickness and colour. The original tacking margins of the painting have been preserved and the ground is present there as well, indicating that this canvas was individually prepared and that the current size is the original size. The unusual pigments found in this ground layer suggest that it was applied in the studio of the artist himself. But could the fact that Steen opted for a lighter, tinted ground suggest that this painting should be dated in Leiden instead
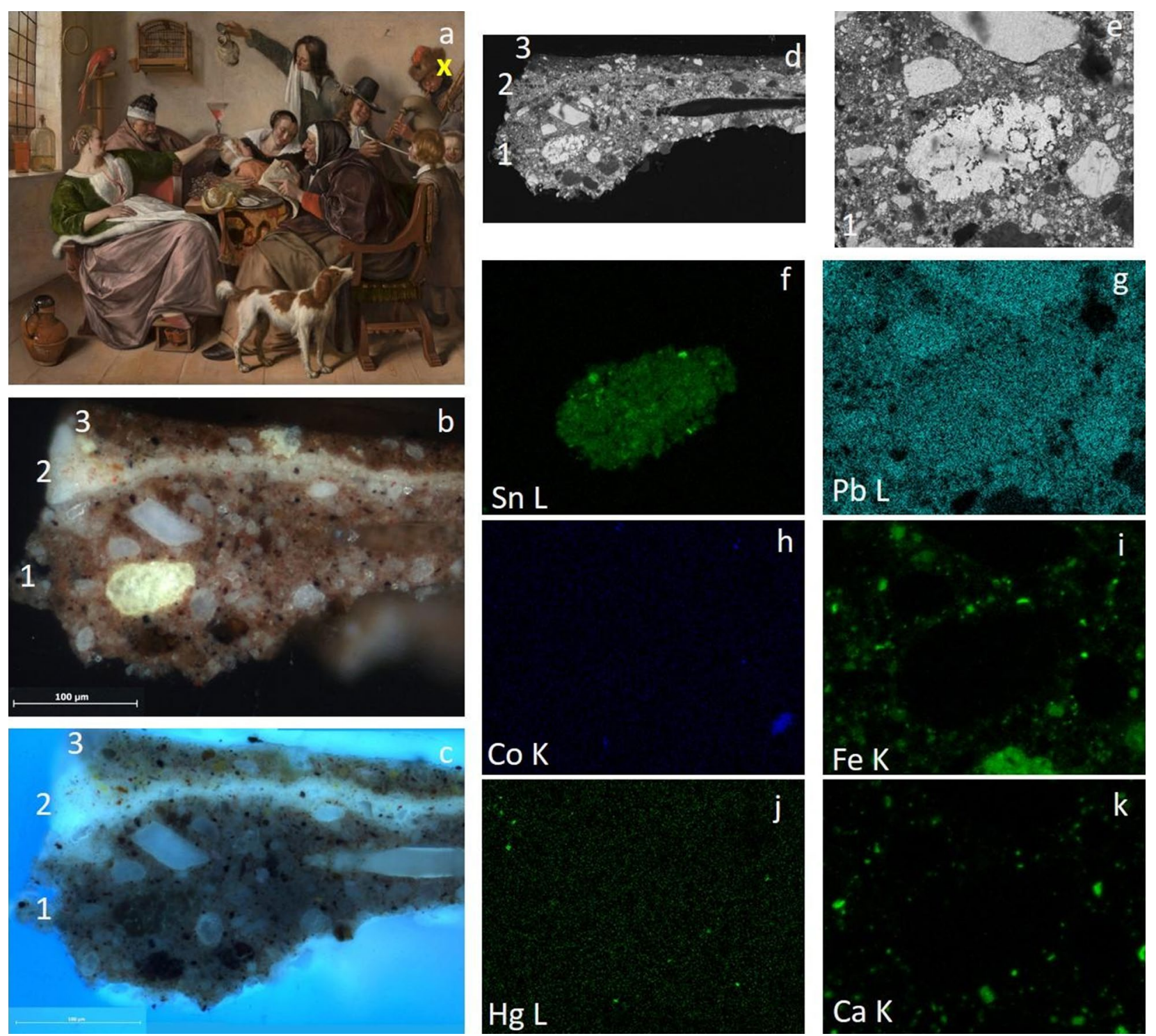

Fig. 8 a 'As the Old Sing, So Pipe the Young', ca. 1668-70, oil on canvas, overview with cross section location marked with yellow X. b Cross section shown in bright field, layer 1 is the ground layer. c Cross section shown in UV. d Backscatter electron image at $\times 250$ magnification. e Backscatter electron image at $\times 1000$ magnification. $\mathbf{f}-\mathbf{k}$ Elemental mappings of different elements, indicating the presence of earth pigments, lead tin yellow, vermillion and smalt 
of Haarlem? The ground layer shows more similarities (both in terms of colour and in terms of materials) with Leiden paintings than with Haarlem paintings, even though it has been applied by Steen himself.

As mentioned above, the bottom ground layers of The Alchemist and The Merry Family also contain unusual pigments. The addition of these pigments, such as smalt, green earth, vivianite, lead tin yellow and vermillion, indicate the use of palette scrapings and thus make it likely the grounds were applied in the studio. Even though Steen seems to have applied these ground layers himself, he does seem to follow local customs by using dark, strongly coloured ground layers consisting mainly of earth pigments in his Haarlem paintings and lighter grounds that are mixtures of lead white, chalk and earth pigments in his Leiden paintings [23].

\section{Conclusions}

Principal Component Analysis is a useful tool for finding correlations and outliers in large and heterogeneous datasets. Special versions of PCA can be used for binary datasets and to analyse datasets of different types in a multi-block setting. In the case of paint samples PCA turned out to be a useful starting point for discovering trends in the elemental composition of large amounts of analysed layers. However, because of the large variety in the samples clusters are not all as sharply defined as one would hope. Interpretation of the PCA outcome remains necessary, taking into account other factors that play a role such as colour of the ground layers.

This research shows that Jan Steen used a variety of ground layers. There is more variation in ground layer composition for the paintings on canvas than for the paintings on panel. With PCA trends could be observed, for both supports. For panel paintings the second ground layer was the distinguishing factor since the bottom ground layers were the same for almost all panel paintings. A cluster of five panel paintings was seen in PCA, of which one painting was dated by Steen himself, when he was living in Haarlem. This suggests the other paintings in this cluster should be dated in Haarlem as well. Moreover, the fact that these panels were all standard sizes suggests that Steen bought them ready-primed.

For canvas paintings several types of grounds were found. These roughly correspond to the cities Steen lived and worked in, suggesting Steen did use locally available materials. In The Hague and Delft a light ground made of a mixture of lead white and chalk was used. The canvas The Tooth-Puller is painted on is cut out of a larger piece of ready-primed canvas. This could indicate that Steen used commercially-prepared canvases while working in Den Haag and Delft, but further research is needed to substantiate this.
A light ground based on lead white, tinted with earth colours, umber and sometimes black pigment is found in several of the analysed paintings made in Leiden. One of the paintings in this cluster, The Mocking of Samson (ca. 1675-76) is unlined and on its original auxiliary support. This could indicate that even though a canvas is individually prepared, it's not necessarily prepared in the artist's studio.

In Haarlem several types of ground layers were used, one of which is a strongly coloured ground. The colour of this bottom ground layer could differ, from dark gray to red. This colour was achieved by using red earth, mixed with chalk in different quantities. In The Oyster Meal (1668) the red ground layer (the only ground layer present in this painting) consists of only earth pigments, while in Life of man (ca. 1665) a bright red bottom ground layer is present consisting of red earth mixed with chalk.

Next to commercially prepared supports Steen also applied his own ground layers. The studio grounds found in this study contain atypical pigments, such as green earth, vermillion, lead-tin yellow and smalt. This indicates the use of palette scrapings. Even though he applied the layers himself, he does seem to follow local customs. In Haarlem the ground layers he applied are strongly coloured, while the studio ground he used in Leiden is tinted.

To continue this research the outcome of PCA will be linked to other technical data on the analysed paintings, such as thread counts, panel sizes and dendrochronology. Also, the use of the ground layer in the final composition of the paintings can be investigated further. To place the results of this study in a wider context comparisons with Steen's contemporaries in the different cities he lived in will be made.

\section{Abbreviations \\ SEM-EDX: Scanning electron microscopy-energy dispersive X-ray spectros- copy; PCA: Principal Component Analysis; MA: Marya Albrecht; OdN: Onno de Noord; SM: Sabrina Meloni; AvL: Annelies van Loon; RH: Ralph Haswell.}

\section{Acknowledgements}

The following institutions are acknowledged for providing paint samples for this research: Rijksmuseum Amsterdam; Museum Boymans van Beuningen Rotterdam; Stedelijk Museum de Lakenhal Leiden; Royal Collections Trust London; National Gallery London; Herzog Anton Ulrich Museum Braunschweig; National Gallery of Art Washington; Koninklijk Museum voor Schone Kunsten Antwerpen; Cultural Heritage Agency of the Netherlands; Salomon Lilian Dutch Old Master Paintings; Jan Six Fine Art; The Matthiesen Gallery and several private collections.

\section{Authors' contributions}

SM sampled all the paintings. SM and RH collected the SEM-EDX data. SM, MA and AvL interpreted LM and SEM-EDX data. OdN performed PCA on the resulting dataset. Interpretation of PCA results was done by MA and OdN. This manuscript was drafted by MA and OdN. All authors read and approved the final manuscript. 


\section{Funding}

This project was a collaboration with Shell Netherlands B.V. Access to the Scientific Department of the National Gallery London was granted through ARCHLAB Transnational Access (part of Iperion CH).

\section{Availability of data and materials}

The datasets used and/or analysed during the current study are available from the corresponding author on reasonable request.

\section{Competing interests}

The authors declare that they have no competing interests.

\section{Author details}

${ }^{1}$ Mauritshuis, Plein 29, 2511 CS The Hague, The Netherlands. ${ }^{2}$ Advanced Data Analysis Consultancy, Kinderhuissingel 112, 2013 AW Haarlem, The Netherlands. ${ }^{3}$ Rijksmuseum Amsterdam, Museumstraat 1, 1071 XX Amsterdam, The Netherlands. ${ }^{4}$ Shell Global Solutions International, Grasweg 31, 1031 HW Amsterdam, The Netherlands.

Received: 10 April 2019 Accepted: 5 July 2019

Published online: 16 July 2019

\section{References}

1. Smith J. A catalogue raisonné of the works of the most eminent Dutch, Flemish and French painters, vol. 8 and supplement. London; 1829-42.

2. Hofstede de Groot C. Beschreibendes und kritisches Verzeichnis der Werke der hervorragendsten Holländischen Maler des XVII. Jahrhunderts, vol. 10. Esslingen am Neckar-Parijs; 1907-28.

3. Braun K. Alle tot nu toe bekende schilderijen van Jan Steen. Rotterdam: Lekturama; 1980.

4. Stols-Witlox M. A perfect ground. Preparatory layer for oil paintings 1550-1900. London: Archetype Publications Ltd; 2017. p. 141-242.

5. Van de Wetering E. Rembrandt, the painter at work. Amsterdam: Amsterdam University Press; 1997. p. 22.

6. Groen K. Grounds in Rembrandt's workshop and in paintings by his contemporaries. In: Van de Wetering E, editor. A Corpus of Rembrandt paintings IV. Dordrecht: Stichting Foundation Rembrandt Research Project; 2005. p. 318-34,660-77.

7. Verslype I, Noble P. Grounds. In: Johnson CR Jr, editor. Counting Vermeer: using weave maps to study Vermeer's canvases. RKD studies. The Hague: RKD; 2017, § 2.5.2 http://countingvermeer.rkdmonographs.nl/chapt er-2-the-use-of-x-radiographs-in-the-study-of-paintings/2.4.2-x-rays-andvermeer2019s-painting-technique/grounds. Accessed 08 Mar 2019.

8. Groen K, Hendriks E. Frans Hals: a technical examination. In: Groen K, editor. Paintings in the laboratory. Scientific examination for art history and conservation. London: Archetype; 2014. p. 135-54.

9. Spring K, Kugler V, Bean S. Quantitative energy dispersive X-ray analysis of the blue pigment smalt in the variable pressure scanning electron microscope. In: Meeks N, Cartwright C, Meek A, Mongiatti A, editors. Historical technology, materials and conservation. SEM and microanalysis. London: Archetype; 2012. p. 114-22

10. Robinet $L$, Spring M, Pagès-Camagna S, Vantelon D, Trcera N. Investigation of the discoloration of smalt pigments in historic paintings by micro $\mathrm{x}$-ray absorption spectroscopy at the Co K-edge. Anal Chem. 2011;83:5145-52.

11. Haswell R, Carlyle L, Mensch CTJ, Hendriks E, Geldof M. The examination of Van Gogh's painting grounds using quantitative SEM-EDX. In: Vellekoop M, Geldof M, Hendriks E, Jansen L, de Tagle A, editors. Van Gogh's studio practice. New Haven: Yale University Press; 2013. p. 202-15.

12. Jolliffe IT. Principal Component Analysis. Berlin: Springer; 1986.

13. Wold S, Esbensen K, Geladi P. Principal Component Analysis. Chemom Intell Lab Syst. 1987;2:37-52.

14. Michailidis $G$, de Leeuw J. The Gifi System of descriptive multivariate analysis. Stat Sci. 1998;13:307-36.

15. de Leeuw J. Canonical analysis of categorical data. Ph.D. thesis, University of Leiden; 1973

16. Kiers HAL. Three-way methods for the analysis of qualitative and quantitative two-way data. Leiden: DSWO Press; 1989

17. Smilde AK, Song Y, Westerhuis JA, Kiers HAL, Aben N, Wessels LFA. Heterofusion: fusing genomics data of different measurement scales. 2019. http://arxiv.org/abs/1904.10279v1.

18. Westerhuis JA, Kourti T, MacGregor JF. Analysis of multiblock and hierarchical PCA and PLS models. J Chemom. 1998;12:301-21.

19. Smilde AK, Westerhuis JA, de Jong S. A framework for sequential multiblock component methods. J Chemom. 2003;17:323-37.

20. Indahl UG, Næs T, Liland KV. A similarity index for comparing coupled matrices. J Chemom. 2018;32:e3049.

21. Verslype I, Noble P. Grounds. In: Johnson CR Jr, editor. Counting Vermeer: using weave maps to study Vermeer's canvases. RKD studies. The Hague: RKD; 2017. § 2.5.2 http://countingvermeer.rkdmonographs.nl/chapt er-2-the-use-of-x-radiographs-in-the-study-of-paintings/2.4.2-x-rays-andvermeer2019s-painting-technique/grounds. Accessed 08 Mar 2019.

22. Wheelock AK Jr. Pieter de Hooch/A Dutch Courtyard/1658/1660. In: Dutch paintings of the seventeenth century. NGA online editions. https://purl. org/nga/collection/artobject/63. Accessed 09 Apr 2019.

23. Apart from the studio grounds found in this study, a ground layer based on smalt and calcium carbonate toned with lead white, earth colours and black was found for the canvas painting Moses Striking the Rock (ca. 1670-1671, Philadelphia Museum of Art), as described in Palmer M, Gifford E.M. Jan Steen's painting practice: the dancing couple in the context of the artist's career. Stud Hist Art. 1997:57:127-55.

\section{Publisher's Note}

Springer Nature remains neutral with regard to jurisdictional claims in published maps and institutional affiliations.

\section{Submit your manuscript to a SpringerOpen ${ }^{\circ}$ journal and benefit from:}

- Convenient online submission

Rigorous peer review

- Open access: articles freely available online

- High visibility within the field

Retaining the copyright to your article

Submit your next manuscript at springeropen.com 